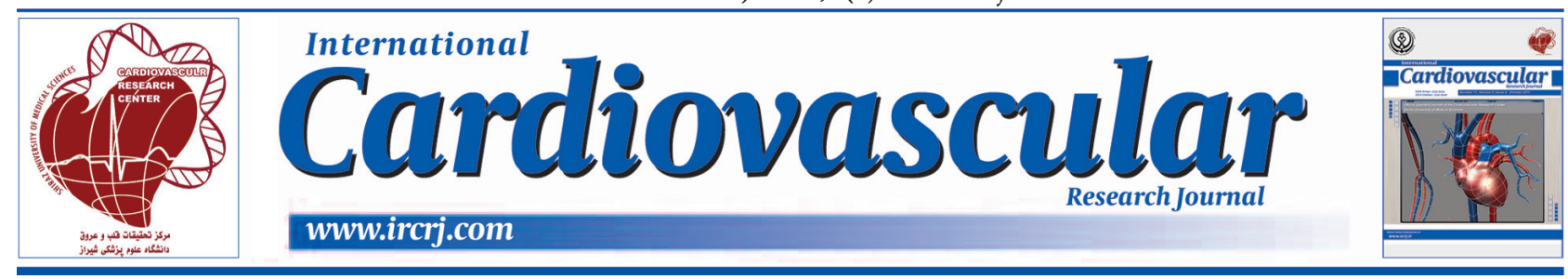

\title{
International Cardiovascular Research Journal and Its Contribution to Iran's Scientific Growth
}

\author{
Mohammad Javad Zibaeenezhad ${ }^{1}$, Mahyar Ahmadpour-B ${ }^{2, *}$ \\ ${ }^{1}$ Cardiovascular Research Center, Shiraz University of Medical Sciences, Shiraz, IR Iran \\ ${ }^{2}$ Cardiovascular Engineering Laboratory, Biomedical Engineering Department, Amirkabir University of Technology, Tehran, IR Iran
}

\begin{tabular}{l}
\hline A R T I C L E I N F O \\
\hline Article Type: \\
Editorial \\
\hline Article History: \\
Received: 12 May 2014 \\
Accepted: 21 May 2014 \\
\hline Keywords: \\
Cardiovascular \\
PubMed \\
\hline
\end{tabular}

International Cardiovascular Research Journal has been recently indexed in PubMed. In order to evaluate the role of this journal in global and international scientific growth, the scientific growth of cardiovascular researches in the past 13 years has been evaluated. In this way, one can compare the role of this journal in Iran and Iran's role in the global scientific growth rate.

Each year, new medical inventions and discoveries all around the world have major influences on increase of public health and decrease of treatment expenditures. It is obvious that in case the results of a study have not been published, that study has not probably been done or reached any result. Therefore, in evaluation of scientific researches, one may think that only published (and indexed) articles should be taken into account. The number of officially indexed articles in acceptable databases is considered as a manifestation of progression in any field. In the field of medical sciences, PubMed is one of the main databases in which each paper is valuable. In addition, the number of indexed papers in PubMed is considered as a good criterion for determining the progresses in medical sciences. This study aims to identify the scientific outcomes in the field of cardiovascular researches both in Iran and around the world during the past 13 years.

*Corresponding author: Mahyar Ahmadpour-B, Cardiovascular Engineering Laboratory, Biomedical Engineering Department, Amirkabir University of Technology, Tehran, IR Iran. Tel: +98-9364129447,

E-mail:mahyar.a@aut.ac.it
According to the statistics, more than 32000 articles were indexed in PubMed during 2000. This figure increased to more than 54000 in 2013, showing a 69\% increase during 13 years. Moreover, 11 articles from or about Iran were indexed in this field during 2000, while this measure was reported to be 550 in 2013, revealing a $5000 \%$ increase in this area. A year-to-year comparison indicates that Iran's publications growth rate in this field has always been higher than that of the world. This implies that cardiovascular sciences have a higher rate in Iran compared to the world. Figure 1 depicts the results of an annual comparison between Iran and the world. In addition, Table 1 shows the exact values of the comparisons presented in Figure 1.

International Cardiovascular Research Journal is a quarterly journal indexed in PubMed which publishes about 40 articles every year. Considering this journal's broad range of authors, it has a significant role in increasing Iran's scientific share and can play even a more significant role in this regard in future.

\section{Acknowledgements}

There is no acknowledgement.

\section{Authors' Contribution}

Both authors have had equivalent roles in the preparation of the paper. 


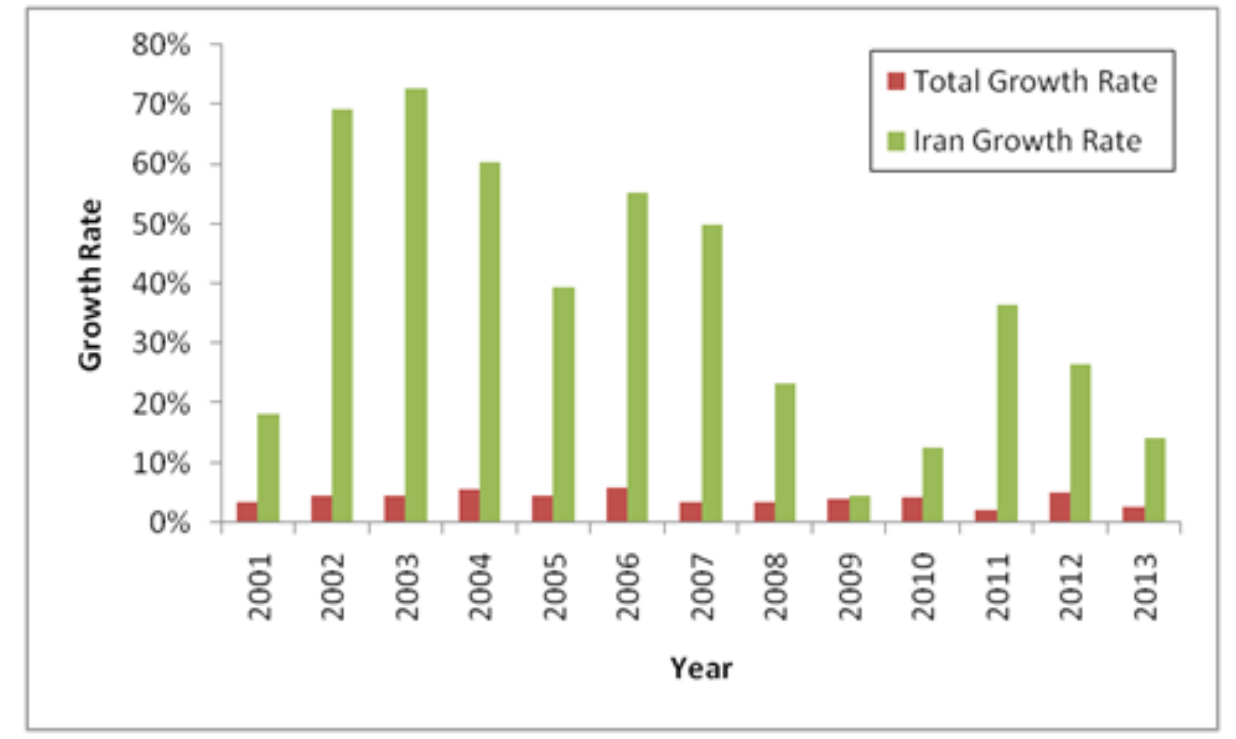

Figure 1. The Annual Scientific Growth Rate in Cardiovascular Researches in Iran and the World

\begin{tabular}{lll}
\hline Table 1. The Annual Number of Articles in the Field of Cardiovascular Researches (1) & \\
\hline Publication Year & Total Articles in PubMed & Articles from or about Iran in PubMed \\
\hline 2000 & 32494 & 11 \\
2001 & 33610 & 13 \\
2002 & 35117 & 22 \\
2003 & 36766 & 38 \\
2004 & 38811 & 61 \\
2005 & 40554 & 85 \\
2006 & 42950 & 132 \\
2007 & 44433 & 198 \\
2008 & 46042 & 244 \\
2009 & 47841 & 255 \\
2010 & 49876 & 287 \\
2011 & 50911 & 392 \\
2012 & 53474 & 496 \\
2013 & 54903 & 566 \\
\hline
\end{tabular}

\section{Financial Disclosure}

There is no financial disclosure.

\section{Funding/Support}

There is no funding/support.

\section{References}

1. US National Library of Medicine NIoH. PubMed; Available from: http://www.ncbi.nlm.nih.gov/pubmed/. Accessed May 10, 2014. 